\title{
Homofobia e Cidade: Um Ensaio Sobre Lâmpadas, Segurança e Medo
}

\author{
Homophobia and City: An Essay About Lamps, Security And Fear \\ La Homofobia y La Ciudad: Un Ensayo Sobre Las Lámparas, La Seguridad Y E1 Miedo
}

\begin{abstract}
Luan Carpes Barros Cassal
Psicólogo. Diretor do Núcleo de Psicologia Educacional da Secretaria Municipal de Educação e Cultura de Itaboraí (RJ). Mestre em Psicologia pela Universidade Federal do Rio de Janeiro. Psicólogo da Secretaria Municipal de Educação e Cultura de Itaboraí. Tem experiência na área de Psicologia, com ênfase em Psicologia Social, atuando principalmente nos seguintes temas: homofobia, educação, psicologia, saúde mental e administração e planejamento em saúde.

E-mail: luancassal@gmail.com
\end{abstract}

\section{Resumo}

O presente texto, um ensaio experimental, surgiu a partir de duas situações de violência homofóbica que ocorreram em Quatorze de Novembro de 2010 e ganharam espaço na grande mídia. Os efeitos de um tiro e de um golpe de lâmpada reverberaram nos corpos e construíram o modo de se relacionar com as outras pessoas e o caminhar pelas cidades. Amplamente divulgada, a homofobia regula as performances de gênero dos sujeitos, esvazia os espaços públicos, fortalece o funcionamento dos sistemas de controle da vida e constrói a cidade como território de medo. As políticas de enfrentamento da homofobia produzem despolitização e individualização das problemáticas sociais e coletivas. Porém, a insistência de corpos andarem pela cidade produziu fraturas nas relações estabelecidas. Assim, possibilitou a experimentação da força e da potência dos encontros inesperados, do corpo e do afeto como formas de resistência, e das lutas cotidianas pelo direito de existir.

Palavras-chave: Homofobia; Cidade; Homossexualidade; Medo

\section{Abstract}

This paper, an experimental essay, has emerged from two cases of homophobic violence that occurred in November Fourteen, 2010 and gained space in the massive media. The effects of a shot and a blow lamp reverberated in how the people has relationships and walk the cities. Publicized, the homophobia regulates the gender performances of people, empties public spaces, strengthens the functioning of life control systems and builds the city as a fear territory. Policies to fight homophobia produce depoliticization and individualization of social and collective problems. However, the insistence of bodies walking through the city brought fractures in establi- 
shed relationships. Thus allowed experience the power of unexpected encounters, the body and affect as resistance forms, and the daily struggle for the right to exist.

Keywords: Homophobia; City; Homosexuality; Fear.

\section{Resumen}

Este artículo es un texto experimental, surgió a partir de dos casos de violencia homofóbica que tuvieron lugar en catorce noviembre de 2010 y que ganaran espacio en los medios de comunicación. Los efectos de un tiro y un golpe de lámpara repercuten en la forma de relacionarse con otras personas y caminar por las ciudades. La homofobia, ampliamente publicitada, regula las actuaciones de género de los sujetos, vacía el espacio público, fortalece el funcionamiento de los sistemas de control de la vida y constroe la ciudad como territorio de miedo. Las políticas de lucha contra la homofobia producen la despolitización y la individualización de los problemas sociales y colectivos. Sin embargo, la insistencia de los cuerpos en caminar por la ciudad ha producido fracturas en las relaciones establecidas. Por lo tanto, esto permitió experimentar la fuerza y el poder de encuentros inesperados, del cuerpo y de los afectos como formas de resistencia y de la lucha diaria por el derecho a existir.

Palabras clave: Homofobia; Ciudad; Homosexualidad; Miedo.

Homofobia e cidade: um ensaio sobre lâmpadas, segurança e medo.

\section{Primeiros Passos: Avenida Paulista}

Madrugada de Quatorze de Novembro de 2010. Avenida Paulista, São Paulo. O coração da cidade que não dorme. Um grupo de jovens gays caminha (alegremente?) pela noite insone. Retornam para casa, ou então se movem para outra balada. Pouco importa.

$\mathrm{Na}$ direção oposta, outro grupo de jovens, divertindo-se pela cidade de uma forma não convencional - agindo como uma polícia dos costumes, carregam porretes e bastões que eliminam as diferenças (Coimbra, 2010). Próximo à estação de metrô Brigadeiro, os dois grupos se cruzam. Repentinamente, um encontro é estabelecido através de uma lâmpada fluorescente. As imagens da agressão e da briga subsequente foram registradas por uma câmera de segurança no local. O sistema de vigilância cumpre seu papel de testemunha dos atos.

Este caso ganhou repercussão nacional na mídia impressa, televisa e digital, com fotos dos ferimentos e principalmente 
imagens gravadas por uma câmera de segurança que registram o uso de uma lâmpada fluorescente na agressão. Chegou aos olhos e ouvidos de um jovem homossexual que se sentiu incomodado. A angústia abriu a possibilidade de escritas diversas sobre as conexões entre o acontecimento e o viver.

Este texto é um ensaio, uma tentativa de dar sentido ao que não é facilmente explicável. Compõem-se aqui memórias, histórias, incômodos, alegrias, reflexões e possibilidades, que experimentam tomar forma. Não pretendemos aqui uma linearidade de fatos ou um crescente de importância. É como uma viagem, em que o importante é o caminho, e não a chegada.

Alguns meses depois, uma viagem levou o jovem para São Paulo. Ele retornava da balada nos arredores da Avenida Paulista. Seguia pela rua em direção à estação de metrô, melhor forma de chegar a sua hospedagem - onde as lâmpadas fluorescentes eram utilizadas para iluminação, antes de seguirem para o lixo. O corpo sentia os passos, o vento frio da noite, o escuro. A Avenida Paulista logo acima o lembrava das lâmpadas que, após se apagarem, poderiam apagar também modos de existência não-hegemônicos. Ele sentia medo: "um projeto estético, que entra pelos olhos, pelos ouvidos e pelo coração" (Batista, 2003, p.75).

Aquela era uma rua escura como tantas outras. Mas tornou-se um território de medo, um temor específico relacionado a um marcador sobre a sexualidade. Há também uma sensação de estranheza. A Avenida Paulista é uma área nobre da cidade de São Paulo, habitualmente frequentada por homossexuais, local da maior Parada do Orgulho LGBT do Brasil, e com alguns estabelecimentos abertos durante a noite. Estes elementos poderiam oferecer segurança para esta situação. Mesmo assim, sentia-se desprotegido. Ser transgressor das normas sexuais é uma marca que não se apaga facilmente; assim, nota-se:

a estranheza com que os 'diferentes' são recebidos, fora de sua zona. (...) Essa quebra do encanto proporcionado pelo projeto estético consumista causa profundo malestar, causa angústia, causa apreensão. (Baptista, 2003, p.108-109)

O consumo não protege da violência, que grita nas ruas e atinge os corpos. A cidade parece estranha, desconhecida e ameaçadora. A sensação de insegurança não está em uma ameaça real, concreta e manifesta, mas sim em um não-reconhecimento do espaço e de seus fluxos. Isso não se deu porque era um território desconhecido, pelo contrário. O que houve foi um acontecimento de violência que fraturou os significados conhecidos daquela rua. A mudança não foi arquitetônica, e sim simbólica. As notícias de jornal que tanto tentam informar fizeram 
da cidade uma estranha, desconhecida e assustadora ameaça em potencial.

\section{Não há lugar como nosso lar: Rio de} Janeiro

De volta a Quatorze de Novembro de 2010, agora no Rio de Janeiro. A Parada do Orgulho LGBT passou por Copacabana, princesinha do mar, e bradou seu tema para todas e todos: orgulho contra o preconceito. Após o evento, algumas pessoas se concentraram ali perto, no Parque Garota de Ipanema, no Arpoador. Casais antigos e novos usavam o espaço escondido da vegetação para encontro com seus desejos e amores. As manifestações afetivas na Parada afirmavam o direito a existir à luz do dia: "Se nessa parada há pessoas transando nas ruas, não é senão para sinalizar onde é que reside a nossa opressão" (Teixeira, 2011, p.63).

Em Quatorze de Novembro, o ponto turístico do Rio de Janeiro, foi território de mais uma violência contra a diferença. Um militar, agente do Estado, gritava: "'viado tem que morrer', 'se matar você, faço um favor para a sociedade' e 'você é uma vergonha para sua família"” (Coimbra, 2010) antes de disparar contra um rapaz homossexual. O tiro comporta duas dimensões diferentes de genocídio; além de (tentar) matar um sujeito pela sua identificação com um determinado grupo social, elimina (talvez mais eficazmente) seu modo de existência. O tiro reafirma a ilegitimidade da diferença, a ilegalidade que deve ser controlada. Batista (2010) descreve este processo com precisão:

\begin{abstract}
O corpo do humilhado torna-se um tipo, um índice, uma diferença formatada na imagem pronta para ser reconhecida e consumida. A força política da humilhação é domesticada perdendo o ímpeto aniquilador do seu ato. Desta outra pele não encontraremos vestígios das nossas histórias. Dos espaços perigosos não encontraremos o passado e o futuro do nosso corpo. Os humilhados serão reduzidos a vítimas ou condenados por atos que só a eles dizem respeito. A diferença brilha solitária, sempre em dívida, comovida ou não com o que extrapola as suas bordas, mas irremediavelmente imaculada. Nada de misturas ou contágios. (Baptista, 2010)
\end{abstract}

A agressão é mais que uma violência individual, uma humilhação localizada. A homossexualidade como vergonha para a família, e o assassinato como favor para a sociedade; a morte, aqui, trata do poder sobre a vida. O sujeito homossexual está ligado à família pela sua relação consanguínea, mas a vergonha fala de um corpo 'degenerado', um sangue 'apodrecido'. A degeneração, um dos maiores medos dos médicos do século XIX (Batista, 2003) continua presente e mancha a orla carioca. A morte (anunciada pelo militar) não tinha um fim nela própria, com a punição do indivíduo 
transgressor. Morrer era útil, matar era 'em defesa da sociedade' (e talvez por isso executada por um funcionário público, agente de segurança): "Esses clamores advindos do pânico cobram sempre o seu preço no corpo dos oprimidos e transformam-se rapidamente em discursos que matam" (Batista, 2003, p.192).

Os militares foram, naquele dia, guardiões da pureza biológica. Um corpo fora do lugar foi marcado, eliminado na diferença que se produzia. A homofobia é transversal; não mata simplesmente indivíduos ou grupos, mas coletivos. Uma produção fascista que elimina as diferenças e a possibilidade de invenções para além das normas. Uma questão de segurança pública que não pode ser pensada de forma individualizada ou repressiva, na medida em que opera constantemente na manutenção do sistema instituído. Conforme nos conta Baptista (2010), os episódios de homofobia muito revelam:

A zona bucólica vista através do vidro despedaçava-se. O bairro seguro foi atravessado por modos de vida fascistas desprovidos de um único autor. $\mathrm{O}$ fascismo individualiza, produz espaço e aniquila qualquer diferença que ouse turvar a paisagem. (...) humilhado, assim como todos os que portam em seus corpos a presença encarnada da cidade produzindo a impertinência do desejo. Chamado de animal perdia a posse em seu corpo da história de outros corpos. Aos animais só restariam os limites da natureza (...) e tudo tem que estar no seu devido lugar. (Baptista, 2010)

Um ano depois, outro casal de jovens gays anda pelas ruas de Ipanema, Rio de Janeiro, de madrugada. Na esquina da Rua Farme de Amoedo, território conhecido pelo público homossexual (predominantemente masculino) que circula e consome, algumas lâmpadas fluorescentes estão largadas no chão, junto ao lixo. Naquela esquina, Ipanema se encontra com a Avenida Paulista. Um corpo está marcado pelo medo daquilo que não viveu. As ruas são vistas como local do perigo, do imprevisível. Talvez seria melhor ficar em casa...

Enquanto isso, o garoto atingido pelo tiro do militar sobreviveu, mas tem medo de sair de casa à noite (www.g1.globo. com). Ele não está na Farme de Amoedo. O disparo deixou cicatrizes no tecido de uma cidade, esvaziando a possibilidade de encontros.

A cidade do medo é também do desencontro. A passagem pelos espaços públicos se dá de forma acelerada, para manter os fluxos do capitalismo em funcionamento. Não há tempo para encontros, não há tempo a perder. A rua deve ser limpa do que atrapalha seu movimento e polui sua pureza. Os dejetos do sistema de produção e os indesejados da sociedade são recolhidos, destruí- 
dos, eliminados; eventualmente reaproveitados e reciclados (Lima, 2012).

Mais um ano se passou. Um novo casal segue percursos da imprevisível noite carioca. Andam de mãos dados pela cidade, abraçados, se beijam. Uma manifestação de carinho mas, intencionalmente ou não, é também um ato iminentemente político em uma cidade asséptica. Seus corpos representam os mais de 200 homossexuais assassinados em 2011 por questões muito específicas:

a noção de homofobia pode ser estendida para se referir a situações de preconceito, discriminação e violência contra pessoas (homossexuais ou não) cujas performances e ou expressões de gênero (gostos, estilos, comportamentos etc.) não se enquadram nos modelos hegemônicos postos por tais normas. (Junqueira, 2007, p. 8-9, grifos no original)

Já esta dupla, brancos, de classe média e com performances predominantemente masculinas (ou seja, próximos de um modelo hegemônico) circula dia e noite, provoca eventuais olhares de estranheza. Nenhum ato de violência física se materializou nesses percursos; não obstante, algumas situações de temor pedem precauções. Mãos se separam, olhos se desviam, a paixão é cortada como navalha pela virtualidade dos acontecimentos e as notícias de jornal. A lâmpada quebrada ilumina a irrealidade de uma sociedade mortificada, massacrada pela violência exibida nas TVs de forma insossa, natural e irreversível.

Conforme descreve Pita (2011), há uma delimitação dos modos de existência considerados legítimos para lésbicas, gays, bissexuais, travestis e transexuais - uma formatação higienizada (de acordo com os padrões ditos saudáveis) das performances de gênero. Em outras palavras, "ser homossexual é possível, contanto que o sujeito siga a cartilha. (...) no caso, troca-se o modelo normativo heterossexual por um modelo normativo homossexual completamente infectado pela misoginia e pelo machismo" (Dodsworth, 2008, pp.16,22). As experimentações da sexualidade são produzidas de forma delineada.

De que forma o encontro é uma ameaça? Por que o prazer do outro a tantos incomoda? A quem interessa o medo instaurado na cidade?

\section{A sexualidade e a cidade}

Foucault $(1979,1988)$ discute a fabricação da sexualidade como um complexo dispositivo de controle e regulação de corpos, vidas, modos de existir: "Existe uma sexualidade depois do século XVIII, um sexo depois do século XIX. Antes, sem dúvida, existia a carne" (Foucault, 1979, p.259). Para Preciado (2008, 2010, 2011), 
as zonas erógenas, os prazeres que sentimos, as práticas sexuais, as performances de gênero, todos estes processos aparentemente naturais são fabricações tecnológicas que servem, de fato, para atender a um sistema hegemônico de produção, ligado a um ciclo de excitação-frustração ininterruptos. Produção serializada de corpos economicamente úteis (Veiga, 2001), como aqueles marcados (de diferentes formas) pela homofobia.

A palavra homofobia foi criada nos anos 70 como uma condição de medo e ojeriza patológica ao sujeito homossexual ou à homossexualidade (Borrillo, 2010). Entretanto, o medo não é uma condição individual. A lâmpada fluorescente largada no lixo do Rio de Janeiro, que remete à violência de São Paulo, não diz de uma ameaça imediata e localizada. O medo se constitui em processos de produção de subjetividade, sempre complexos e coletivos (Guattari \& Rolnik, 1996). O medo é fabricado, se organiza e se espalha de acordo com diversos interesses.

O desenho da cidade que é feito pela homofobia regula o modo como os corpos circulam. Aos homossexuais, melhor performarem seus gêneros de acordo com o padrão esperado. Nada de manifestações de afeto em público, ou de 'dar pinta' para os homens ou 'ser masculina' para as mulheres. Se possível, em nome da segurança individual, a circulação deve ser de carro, e o consumo em territórios bem específicos. No Rio de Janeiro, jante na Rua Farme de Amoedo; em São Paulo, vá à balada na Rua Frei Caneca. Sinta-se protegido nos estabelecimentos que são 'amigáveis' e ‘tolerantes' - desde que você possa consumir, claro. E os corpos indesejados, negras, negros, pobres, travestis, transexuais, continuam trabalhadoras exploradas, muitas vezes no mercado do sexo. Para atender a um sistema econômico, são vulneráveis, descartáveis, desejáveis por um momento com seus corpos a venda (Preciado, 2010).

Em uma sociedade de controle (Deleuze, 1992), não há garantias para a vida. O controle se dá ao céu aberto, está em nossos corpos, nas cifras de identificação que se modificam o tempo todo. O jovem homossexual que anda pela Avenida Paulista de madrugada, no final do verão, se lembra dos vídeos exibidos com a lâmpada fluorescente utilizada em um rapaz, que poderia ser seu colega, seu amigo, seu primo, ele próprio. Modifica sua performance de gênero para atender às programações preestabelecidas. Em uma decisão tomada rapidamente, ao ver um grupo de pessoas vindo na direção oposta, elimina seu modo de existência para evitar a violação de sua integridade física. $\mathrm{O}$ sistema produtivo se impõe uma vez mais. Não são mais necessários policiais, psicólogos, pedagogos, pastores da alma que vigiem o corpo. O controle está entranhando 
nas performances, nos modos de existir, e tem o esvaziamento político da cidade como estratégia: "Segundo a lógica das sociedades de controle, a privatização dos meios públicos é a maneira de controlar os encontros casuais capazes de proporcionar divergências e alternativas geradoras de impasse" (Maciel, 2007).

Esta ficção constrói corpos, produz subjetividades, compõe relações de poder. Por um lado, esquadrinha as transgressões possíveis e retira seu potencial político, marcando sujeitos enquanto vítimas de sua própria existência (Baptista, 1999). E para além disso, organiza a visibilidade do sistema de normatizações sobre o sexo. Conforme indica Foucault (1987), a construção de códigos penais, mais do que eliminar as ilegalidades, faz seu gerenciamento: dá maior visibilidade a algumas transgressões, mantendo outras quase esquecidas. Da mesma forma, a normatividade homossexual chama atenção de alguns comportamentos realizados por grupos de pessoas assim identificadas. A identidade dita como homossexual é atravessada pela afirmação ou rejeição destes comportamentos, enquanto a heterossexualidade passa 'desapercebida' nestes mesmos territórios existenciais.

A visibilidade da homossexualidade, o enfrentamento do estigma de 'promiscuidade' ou transgressão, a necessidade de se provar como um sujeito 'de bem', a culpa- bilização e individualização das agressões; gestão das ilegalidades para manutenção do sistema. Transformação dos corpos, modelação das subjetividades. O medo é uma estratégia potente.

\section{A utilidade da homofobia}

O que produzia a sensação de insegurança nessas várias histórias? Talvez a ausência de um agente de Estado, fazendo vigilância e proteção, para manutenção da Ordem. Quem garantiria o cumprimento das leis e a proteção dos indivíduos? Afinal, a lâmpada não se moveu sozinha em São Paulo; na verdade, ela estabeleceu relações entre dois corpos transgressores. Um primeiro desobedecia leis penais para atingir um segundo, violador das normas sexuais.

As mídias divulgam características que supostamente permitiriam identificar indivíduos homofóbicos, tais como classe social, gênero, local de moradia, escolaridade, preferências políticas, identidades, performances estéticas, atestadas por diversos saberes psis. A psicologia explica a homofobia como dado individual; com isso, produz o medo do espaço público, onde pode ocorrer o perigoso encontro. O medo produz o desejo por um agente de segurança que regule o funcionamento do espaço e do tempo na cidade e que garanta as lâmpadas em seus lugares. Não é mais necessária uma 
vigilância imposta. Clama-se por mais policiamento para reprimir a criminalidade, e teme-se porque nunca é o suficiente (Cassal, 2012, no prelo).

Ora, a homossexualidade e a homofobia são construções que hoje estão instituídas e, portanto, precisam ser interrogadas. A criação de categorias psicológicas ou psiquiátricas serve para a naturalização do indivíduo homofóbico como um dado natural, com efeitos estratégicos de poder. De tantas possibilidades de enfrentamento à homofobia, a individualização do problema com a identificação, contenção e correção de indivíduos perigosos se torna a mais óbvia e estabelecida.

A homofobia produz medo porque é imprevisível. Pode acontecer a qualquer hora, em qualquer lugar, com qualquer pessoa; não é possível identificar previamente quem será o 'homofóbico'. Há apenas a suspeita, e a produção de uma insegurança constante. Assim, o medo induz e justifica políticas repressoras para controle social das diferenças e manutenção da ordem instituída (Batista, 2003). Através do medo, a violência movimenta um imenso mercado financeiro; o serviço de segurança privada é um negócio lucrativo para inúmeras pessoas e empresas (Minayo, 2006). O medo torna-se algo individual e problema de polícia, enquanto ignora-se a complexidade das situações que se apresentam no contemporâ- neo. Ou seja, o medo da homofobia agencia outros genocídios. O medo funciona como uma tecnologia política, que movimenta uma economia desejada; o medo produz um grande controle com um mínimo de esforço. E o perigo que ronda este espaço é a reafirmação dos homossexuais como corpos transgressores das normas instituídas sobre sexualidade:

$$
\begin{aligned}
& \text { homofobia e zonas perigosas são } \\
& \text { denominações utilizadas para designar } \\
& \text { atitudes e áreas da cidade. Na mídia, } \\
& \text { assim como nos textos acadêmicos, a } \\
& \text { psicopatologia da almahumana e topografia } \\
& \text { urbana explicariam a origem das mazelas } \\
& \text { da atualidade. Em determinadas áreas da } \\
& \text { urbe e da alma estariam alojadas as razões } \\
& \text { da violência. Em certos corpos, psiquismos } \\
& \text { ou cantos da cidade, impermeabilizados } \\
& \text { por suas individualidades, residiria o mal } \\
& \text { passível de cuidado ou extirpação. (Baptista, } \\
& \text { 2010) }
\end{aligned}
$$

A homofobia é fundamental para a sustentação do dispositivo da sexualidade e das estratégias de biopoder (Cassal, 2012). A violência compõe processos de produção de subjetividade que produzem o espaço urbano de determinadas formas. Conforme aponta Batista (2003, p.204), “os discursos do medo têm consequências estéticas, criam monumentos, transformam a cidade". A Avenida Paulista torna-se um museu da violência homofóbica ao céu aberto, enquanto 
as notícias da mídia são guias turísticos, pretensamente neutros e desinteressados que apenas retratam o que está ali. A cumprir seu papel, reafirmam o funcionamento das estratégias de poder:

Nossa história nos aponta não para o fim desses atos, mas para a reedição e aperfeiçoamento dessas mórbidas estratégias. [...] as ruas de São Paulo, as praias do Rio de Janeiro, são espaços que estilhaçam os espelhos de uma burguesia que se deseja ver asséptica, segura e feliz. São espaços que estilhaçam uma ética que se diz universal, mas que necessita da ação da polícia e das grades dos condomínios fechados para o seu bom funcionamento. (Baptista, 1999, p.47)

Mais do que indivíduos considerados transgressores, grupos inteiros são chacinados; ora pela eliminação dos corpos pulsantes, ora pelo genocídio do silêncio e da invisibilidade. Atualmente, o critério para demarcação de anormalidade é menos o corpo transgressor e mais "o grupo social ao qual esse corpo está indissoluvelmente ligado" (Veiga, 2001, p. 107). Os corpos transgressores agredidos são vistos (de forma focal e pontual nos noticiários), mas o mesmo não pode ser dito das populações eliminadas. As 200 pessoas assassinadas em 2011 não estão na TV. A dimensão coletiva é silenciada, e a violência torna-se questão de risco individual. Assim, o medo é estratégico na manutenção deste sistema, pois o "olhar cotidiano indiferente à miséria e às torturas e mortes violentas dos pobres (...) precisa de um discurso que explique e naturalize o macabro espetáculo global. É por isso que esses discursos do medo se difundem pelas telas, pelas bancas" (Batista, 2003, p.119). Um estado democrático dos direitos de alguns.

\section{Por uma outra cidade}

Os primeiros espaços de retorno sistemático de humanos se constituíram como territórios de rituais, de despedida dos mortos, de troca e partilha de significados comuns. $\mathrm{O}$ encontro vem antes da demanda de proteção. Falar de possibilidades da cidade não é a expectativa de retorno a um estado mais puro; conforme aponta Haraway (2009), não há uma forma original, pois fazemos parte de sistemas produtivos que envolvem conexões variadas. A identificação de algo como natural ou dado a-histórico já é uma construção tecnológica. O que está em jogo é a construção de outras formas de estar na cidade. Possibilidades que fogem à normatização, e que incomodam. A homossexualidade pode ser uma potência para a experiência da cidade, pois: 
é isto o que torna "perturbadora" a homossexualidade: o modo de vida homossexual muito mais que o ato sexual mesmo. Imaginar um ato sexual que não seja conforme a lei ou a natureza, não é isso que inquieta as pessoas. Mas que indivíduos comecem a se amar: ai está o problema. A instituição é sacudida, intensidades afetivas a atravessam; ao mesmo tempo, a dominam e perturbam (Foucault, 1981)

O encontro da homossexualidade pode afrontar o modo institucionalizado de funcionamento dos corpos e das paixões. Enquanto a televisão registra a violência e o medo; enquanto psicólogos falam do sofrimento e defendem o retorno à heterossexualidade quando assim desejado; enquanto militantes dizem que a vergonha é vivência intrínseca aos parentes; enquanto um militar atira em defesa da sociedade; enquanto isso, dois jovens andam alegres, de mãos dadas, por partes da cidade. Este encontro dá visibilidade à dimensão processual do dispositivo da sexualidade: se as regras, os prazeres e as vivências são construídos, também são passíveis de desconstrução. As mãos dadas trazem novos sentidos para a rua, e perguntam se as relações devem ser apenas as padronizadas. A garantia de um casamento civil, um contrato, permitira que eles andassem pela cidade?

Talvez o medo também componha a experiência de andar pela cidade. Mas constitui-se uma trama afetiva intensa, que sustenta o enfrentamento das adversidades (Foucault, 1981). Estar enamorado nas ruas não era algo fácil ou livre de preocupações. Não é que se estivesse seguro. Mas não se estava só: era possível enfrentar as adversidades em conjunto. Os seus modos de existência, ao ganhar espaço no público, tornaram-se instrumentos de uma luta política pela multiplicidade. Os dois são parceiros de armas, companheiros de guerrilha, compartilhando o momento e os movimentos. Seus corpos também foram violados pelo Quatorze de Novembro, mas não foram destruídos - as marcas compõem experiências, fraturam verdades naturalizadas, possibilitam novos caminhos. A luta não é individual nem solitária pois, como Baptista (2012) conta a história de um ninguém: "Não gemi de dor sozinha. A dor que senti foi, e ainda é de muita gente. (...) O meu sangue tem história". Na cidade, houve o encontro das experiências e a composição de uma força transversal. O enfrentamento da homofobia está na prática cotidiana, no encontro que pode inquietar os afetos e formar outras formas de aliança: "[Dois homens] Terão que inventar de A a Z uma relação ainda sem forma que é a amizade: isto é, a soma de todas as coisas por meio das quais um e outro podem se dar prazer" (Foucault, 1981). O encontro homossexual pode abrir possibilidades de encontros dife- 
rentes com a cidade, como pensam Knijnik e Guizzo (2012):

vale-se aqui da história e de uma suposta origem da cidade não para apontar a verdade encontrada, mas para atrelá-la a um sentido positivo e criativo; e também para que as Ideias que vinculam o surgimento da cidade a funções ordinárias (sobrevivência), a motivos de proteção (medo) ou ainda ao sentido de progresso (evolução) possam ser problematizadas. (Knijnik \& Guizzo, 2012, p.175)

Hoje, as principais estratégias de enfrentamento da homofobia passam pela visibilidade massiva das Paradas do Orgulho LGBT, pela criminalização da homofobia e por campanhas de denúncia de violências e agressões com cartazes, levantamentos de dados e centros de referência. Modos de enfrentamento que estão centrados na eleição de um inimigo, na construção de um sujeito perigoso, na política da individualização, na reafirmação do controle do viver (Cassal, 2012). Mas antes de uma cidade de medo, precisamos de uma cidade de encontros. E assim, meio sem querer, os corpos dos dois jovens seguiam um outro caminho, traçando linhas diagonais no tecido social, fazendo emergir outros possíveis. $\mathrm{O}$ encontro não propunha (a priori) o embate, o enfrentamento, a demarcação de um lugar de oposição ao instituído, pautado pela dicotomia permitido-proibido. Pelo contrário, caminhavam na fabricação de um comum no espaço público. Seus corpos não estavam prontos para a batalha, permitiam ser afetados pela fragilidade do imprevisível. A luta não era significada como certeza, e sim enquanto consequência possível, dentre inúmeras outras. Estar de mãos dadas pode não ser fértil no sentido biológico, mas é fecundo de possibilidades. O encontro era forjado pelo prazer de estar ali, de ter ou não as mãos entrelaçadas, com um olhar mais ou menos intenso. Uma atitude chamada por Rosa e Cassal (2013) de 'doçura', atravessada pela produção de desejo e curiosidade, provocativa em sua fragilidade, meiga e leve em seus movimentos. A doçura é intensa dentro de um contexto social de discursos de medo da cidade; o doce se faz no contraste com o salgado do sangue e o amargor do contemporâneo. A cidade era repensada como um território de possíveis.

Estar junto não é uma certeza, nem uma promessa. É um breve momento de paz, que logo se esfacela no turbilhão da cidade. Os fluxos separam as pessoas, exigem mudanças e revoluções diárias. Ao mesmo tempo, os processos da homofobia marcam mais corpos, histórias, famílias e eliminam as possibilidades de ser, de amar. E o que fica?

Para além de fórmulas ou certezas, de expectativas de modificação do outro, o que fica em nós é a possibilidade de experimentar invenção de um lugar-comum, pautado na 
fragilidade exposta, no cuidado, na entrega e numa escuta sensível. O estar-juntos, em constante diálogo, fortalece a possibilidade de reinvenção dos (nossos) corpos, de afirmação das singularidades, geradores de um comum realmente múltiplo e diverso, difícil de conquistar, mas prazeroso de se construir (Rosa \& Cassal, 2013, p.8)

O que fica para continuar? Memórias de uma cidade em que se pode caminhar dia ou noite. Marcas corporais de um tombo, de um beijo, do medo da violência. Pequenos sussurros no vento frio. $\mathrm{O}$ vento frio da noite de São Paulo se torna o movimento do ar de liberdade no Rio de Janeiro. Enquanto a homofobia tranca os corpos em performances pré-determinadas e espaços fechados, há outros modos possíveis de enfrentamento, que passam pela cidade e pelos modos de existência, com abertura para as múltiplas possibilidades. E que estas sejam caminho não (só) de medo, e sim das lutas cotidianas pelo direito de existir.

\section{Referências}

Baptista, L. A. S. (1999). A atriz, o padre e a psicanalista - os amoladores de facas. In: . Cidade dos Sábios. São Paulo: Summus, pp. 45-49.
Baptista, L. A. S. (2010). Cenas de um corpo sem dono. Jornal do Grupo Tortura Nunca Mais/RJ, ano 24, no 74.

Baptista, L. A. S. (2011). Oração de um nenhum a nossa senhora dos desvalidos. Jornal do Grupo Tortura Nunca Mais/RJ - ano 25 - $\mathrm{n}^{\mathrm{o}} 78$.

Batista, V. M. (2003). O medo na cidade do Rio de Janeiro: dois tempos de uma história. Rio de Janeiro: Revan.

Borrillo, D. (2010). Homofobia: História e crítica de um preconceito. Belo Horizonte: Autêntica.

Cassal, L. C. B. (2012). Tiros, Lâmpadas, Mapas e Medo: Cartografias da homofobia como dispositivo de biopoder. Dissertação de mestrado. Curso de Pós-Graduação em Psicologia, Universidade Federal do Rio de Janeiro, Rio de Janeiro.

Cassal, L. C. B. (No prelo). Psicologia e Homofobia: uma cartografia de encontros, embates e políticas. Cadernos do VI Prêmio Margarete de Paiva Simões Ferreira.

Coimbra, M. C. B. (2010). Homofobia: o fascismo social avança. Jornal do Grupo Tortura Nunca Mais/RJ, ano 24, n. 74.

Deleuze, G. (1992). Post-scriptum sobre as sociedades de controle. In: 
Conversações: 1972-1990. Rio de Janeiro: Editora 34, pp. 219-226.

Dodsworth, A. (2008). Identidade gay e os preconceitos que cerceiam a intolerância - o olhar de Foucault e Deleuze. Filosofia, Ciência e Vida, n. 22 ano II, São Paulo, pp. 14-23.

Foucault, M. (1979). Microfísica do Poder. Rio de Janeiro: Graal.

Foucault, M. (1981). Da amizade como modo de vida ("De l'amitié comme mode de vie). Jornal Gai Pied, n. 25, p.38-39. Tradução de Wanderson Flor do Nascimento, disponível em: $\quad<$ www.filoesco.unb.br/foucault $>$. Consultado em: 23 jun. 2011.

Foucault, M. (1987). Vigiar e Punir: nascimento da prisão. Petrópolis: Vozes.

Foucault, M. (1988). História da Sexualidade I: A vontade de saber. Rio de Janeiro: Graal.

Guattari, F. \& Rolnik, S. (1996). Micropolítica: Cartografias do desejo. Petrópolis: Vozes.

Haraway, D. J. (2009). Manifesto Ciborgue: ciência, tecnologia e feminismosocialista no final do século XX. In: Tadeu, T. (org). Antropologia do ciborgue: as vertigens do póshumano. Belo Horizonte: Autêntica, p.33-118.
Junqueira, R. D. (2007). Homofobia: limites e possibilidades de um conceito em meio a disputas. Bagoas: Estudos gays, gêneros e sexualidades, v. 1, pp. 1-22.

Knijnik, C. \& Guizzo, I. (2012). Troca de segredos: um dispositivo que contagia experiências.In: BAPTISTA, L. A. S. \& Santana, M. F. (org) Por que a cidade. Niterói: Editora da UFF.

Lima, T. G. (2012). Tramas insones da cidade. In: Baptista, L. A. S. \& Santana, M. F. (org) Por que a cidade. Niterói: Editora da UFF.

Maciel, A. (2007). Clínica, indeterminação e biopoder. In: Comissão de Direitos Humanos do CRP-RJ (org). Direitos Humanos? O que temos a ver com isso? Rio de Janeiro: Conselho Regional de Psicologia - RJ.

Minayo, M. C. S. (2006). Violência e saúde. Rio de Janeiro: Editora FIOCRUZ.

Pita, I. (2011). Homonormatividade. Porque gay também é limpinho. Disponível em: $\quad<$ http://politicaativa.gay1.com. br/2011/11/homonormatividade-porquegay-tambem-e.html\#>. Consultado em: 28 nov. 2011.

Preciado, B. (2008). Testo Yonqui. Madrid: Espasa.

Preciado, B. (2010). Pornotopia: Arquitectura y sexualidad em 
"Playboy" durante la guerra fría. Barcelona: Anagrama.

Preciado, B.(2011). Manifiesto contrasexual. Barcelona: Anagrama.

Rosa, T. \& Cassal, L. C. B. (2013). Compartilhar a experiência: Eu Vírgula Você e Eu. $C T R L+A L T+D A N C ̧ A . \quad$ Disponível em: <http://ctrlaltdanca.com/2013/04/04/ textos-tulio-rosa-e-luan-cassal-propoemreflexoes-sobre-participacao-intimidade-eperformance-em-eu-virgula-voce-e-eu/>. Consultado em: 04 abr. 2013.
Teixeira Filho, F. S. (2010). Os segredos da adoção e o imperativo da matriz bioparental. Revista de Estudos Feministas, v.18, n.1, pp. 241-261.

Veiga Neto, A. Incluir para excluir. (2001). In: Larrosa, J. \& Skliar, C. (org.). Habitantes de Babel: políticas e poéticas da diferença. Belo Horizonte: Autêntica, pp. 105-118.

Recebido em: 01/09/2013 - Aceito em: 18/11/2013 